\title{
EVALUATION OF THE SPACE SHUTTLE TRANSATLANTIC ABORT LANDING ATMOSPHERIC SOUNDING SYSTEM
}

\author{
Frank B. Leahy* \\ NASA Marshall Space Flight Center, Huntsville, Alabama
}

\begin{abstract}
This paper describes a study that was conducted to determine the quality of thermodynamic and wind data measured by the Space Shuttle Transatlantic Abort Landing (TAL) Atmospheric Sounding System (TASS). The system has Global Positioning System (GPS) tracking capability and provides profiles of atmospheric parameters such as temperature, relative humidity, and wind in support of potential emergency Space Shuttle landings at TAL sites. Ten comparison flights between the Low-Resolution Flight Element (LRFE) of the Automated Meteorological Profiling System (AMPS) and TASS were conducted at the Eastern Test Range (ETR) in early 2002. Initial results indicated that wind, temperature, and relative humidity compared well. However, incorrect GPS settings in the TASS software were resulting in altitude differences of about 60 to 70 $\mathrm{m}(-200$ to $230 \mathrm{ft})$ and air pressure differences of approximately 4 hectoPascals $(\mathrm{hPa})$. TASS software updates to correct altitude data were completed in early 2003. Subsequent testing showed that altitude and air pressure differences were generally less than $5 \mathrm{~m}$ and 1 $\mathrm{hPa}$, respectively.
\end{abstract}

\section{INTRODUCTION}

The previous system used for measurements of upper air thermodynamic and wind environment at Space Shuttle TAL sites was the Radio Automatic Theodolite Sounder (RATS). A replacement system was needed because RATS was obsolete and sondes were no longer in production. The Sippican W-9000 Meteorological Processing System with GPS tracking capability was selected to replace RATS and was referred to as TASS. In response to a request from the Space Shuttle Program (SSP), an analysis was conducted to determine the quality of thermodynamic and wind data measured by TASS. To accomplish this, 10 comparison flights between TASS and the AMPS LRFE were executed at the ETR in early 2002. Based on an earlier analysis, thermodynamic and wind data quality of the AMPS LRFE was determined to be suitable for Space Shuttle operations ${ }^{1}$. Therefore, the AMPS LRFE was used as

\footnotetext{
*Aerospace Technologist, Flight Vehicle Atmospheric Environments
}

the standard reference in the evaluation of TASS thermodynamic and wind data.

\section{SYSTEM DESCRIPTION}

TASS is a commercial off the shelf (COTS) version of AMPS. Both systems use the Sippican Line Of Sight (LOS) GPS Mark II Microsonde to generate meteorological and low-resolution wind data. Wind speed, wind direction, and altitude are calculated from GPS data. Temperature is measured with a thin, fast response rod thermistor. Relative humidity is measured with a fast response carbon hygristor. Pressure and density are derived from GPS altitude, temperature, relative humidity, and surface pressure. The flight package for TASS consists of the Sippican Mark II Microsonde attached $21 \mathrm{~m}$ (70 ft) below a standard latex weather balloon. This configuration is very similar to the AMPS LRFE. The fundamental difference between the AMPS LRFE sonde and the Mark II Microsonde is in the transmitter. The AMPS LRFE sonde is programmable to operate at one of sixteen discrete frequencies with a narrow $(20 \mathrm{kHz})$ deviation. This provides AMPS the capability to track up to six sondes simultaneously. The TASS Mark II Microsonde transmitter is continuously tunable with a broader $(400$ $\mathrm{kHz}$ ) deviation. TASS is capable of tracking only one sonde at a time. Both transmitters operate between 400 and $406 \mathrm{MHz}$.

\section{DATA}

Thermodynamic and low-resolution wind data were collected during 10 TASS/AMPS LRFE comparison flights at the ETR in February, March, and April of 2002. Five of the flights were simultaneous releases of a TASS balloon and an AMPS LRFE balloon. The other five flights were in a configuration where the TASS sonde and AMPS LRFE sonde were attached to the opposite ends of a boom suspended below the balloon. This configuration allowed the two sondes to remain at the same altitude during their ascent. Data files obtained from both systems included raw 1-second data and $305 \mathrm{~m}(1000 \mathrm{ft})$ data. A listing of the 10 flights is given in Table 1. Temperature and pressure analyses for flight 5 were not conducted due to erroneous temperature data reported by the TASS sonde. 
Table 1. Listing of TASS/AMPS LRFE comparison flights.

\begin{tabular}{ccc}
\hline Flight \# & Date (Time) & Configuration \\
\hline 1 & $\begin{array}{r}02 / 12 / 02 \\
(1525 \mathrm{Z})\end{array}$ & Simultaneous Release \\
\hline 2 & $\begin{array}{r}02 / 14 / 02 \\
(1120 \mathrm{Z})\end{array}$ & Simultaneous Release \\
\hline 3 & $\begin{array}{r}02 / 22 / 02 \\
(1535 \mathrm{Z})\end{array}$ & Simultaneous Release \\
\hline 4 & $\begin{array}{r}03 / 04 / 02 \\
(1125 \mathrm{Z})\end{array}$ & Simultaneous Release \\
\hline 5 & $\begin{array}{r}03 / 12 / 02 \\
(1625 \mathrm{Z})\end{array}$ & Simultaneous Release \\
\hline 6 & $\begin{array}{l}04 / 01 / 02 \\
(1615 \mathrm{Z})\end{array}$ & Boom \\
\hline 7 & $\begin{array}{r}04 / 02 / 02 \\
(1445 Z)\end{array}$ & Boom \\
\hline 8 & $\begin{array}{r}04 / 09 / 02 \\
(1445 \mathrm{Z})\end{array}$ & Boom \\
\hline 9 & $\begin{array}{l}04 / 10 / 02 \\
(1445 \mathrm{Z})\end{array}$ & Boom \\
\hline 10 & $\begin{array}{l}04 / 16 / 02 \\
(1500 \mathrm{Z})\end{array}$ & Boom \\
\hline
\end{tabular}

Wind

\section{DATA ANALYSIS}

The quality of TASS wind data was evaluated by determining the vector error estimate (VEE) in wind for each of the ten test flights. The VEE was calculated at corresponding $305 \mathrm{~m}$ levels with

$$
V E E=\sqrt{(\Delta U)^{2}+(\Delta V)^{2}}
$$

where $\Delta U$ is the difference (AMPS LRFE - TASS) in the west to east vector wind component and $\Delta V$ is the difference in the south to north vector wind component. The mean, standard deviation, and root-mean-squared (RMS) of the VEE were calculated for each test flight. Figure 1 shows the $U$ and $V$ wind component profiles and VEE for flight $10(04 / 16 / 02$ 1500Z). Table 2 lists the VEE statistics for each of the ten test flights and the total for all flights. All flights compared well with RMS VEE values less than $1.5 \mathrm{~m} / \mathrm{sec}$.

Both systems incorporate wind-finding algorithms that reduce the pendulum effect of a sonde on a $21 \mathrm{~m}$ train. The addition of a boom on the balloon for flights $6-10$ could introduce errors in the calculated wind. However, it was anticipated that the errors in both sondes would be identical and cancel. Examination of Table 2 reveals
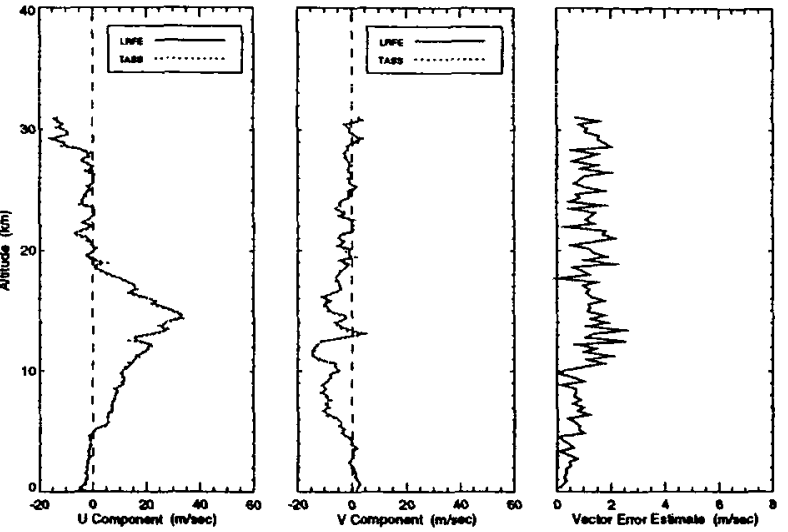

Figure 1. $U$ and $V$ wind component profiles for AMPS LRFE/TASS test flight 10 and VEE profile (far right).

Table 2. VEE statistics for each of the ten AMPS LRFE/TASS comparison flights and total for all flights.

\begin{tabular}{c|ccc}
\multirow{2}{*}{$\begin{array}{c}\text { Flight } \\
\#\end{array}$} & \multicolumn{3}{|c}{ VEE $(\mathrm{m} / \mathbf{s e c})$} \\
\cline { 2 - 4 } & Mean & Std Dev & RMS \\
\hline 1 & 0.31 & 0.89 & 0.94 \\
2 & 0.55 & 1.18 & 1.29 \\
3 & 0.69 & 1.01 & 1.21 \\
4 & 0.49 & 1.17 & 1.27 \\
5 & 0.80 & 1.27 & 1.49 \\
6 & 0.58 & 0.83 & 1.01 \\
7 & 0.55 & 0.73 & 0.91 \\
8 & 1.18 & 1.19 & 1.67 \\
9 & 0.80 & 0.64 & 1.02 \\
10 & 0.64 & 0.55 & 0.84 \\
\hline Total & 0.66 & 0.97 & 1.17
\end{tabular}

that RMS VEE values for the boom flights were generally less than those for the simultaneous release flights (flights $1-5$ ). This could mean that either the effect of the boom was small or cancelled, or that the spatial separation of the simultaneous release balloons resulted in larger VEE values.

\section{Temperature}

TASS temperature data quality was evaluated by determining the difference (AMPS LRFE - TASS) in temperature at corresponding $305 \mathrm{~m}$ levels. The mean, standard deviation, and RMS temperature differences were calculated for nine of the ten test flights (flight 5 had erroneous TASS temperature). Figure 2 shows the AMPS LRFE and TASS temperature profiles and the temperature difference for test flight 7 on $04 / 02 / 02$ at 1445Z. Table 3 lists the temperature difference statistics

2

American Institute of Aeronautics and Astronautics 
for the nine test flights and the total for all flights. On average, the TASS temperature was about $0.2^{\circ} \mathrm{C}$ colder than the AMPS LRFE temperature. The overall RMS temperature difference was $0.49^{\circ} \mathrm{C}$. Another study has shown that the system variability of the AMPS LRFE for temperature was about $0.4^{\circ} \mathrm{C}^{\prime}$. Therefore, an RMS temperature difference of $0.49^{\circ} \mathrm{C}$ in this study was considered acceptable. There appeared to be no significant variation in temperature differences between the boom releases (flights 6-10) and the simultaneous releases (flights $1-4$ ).
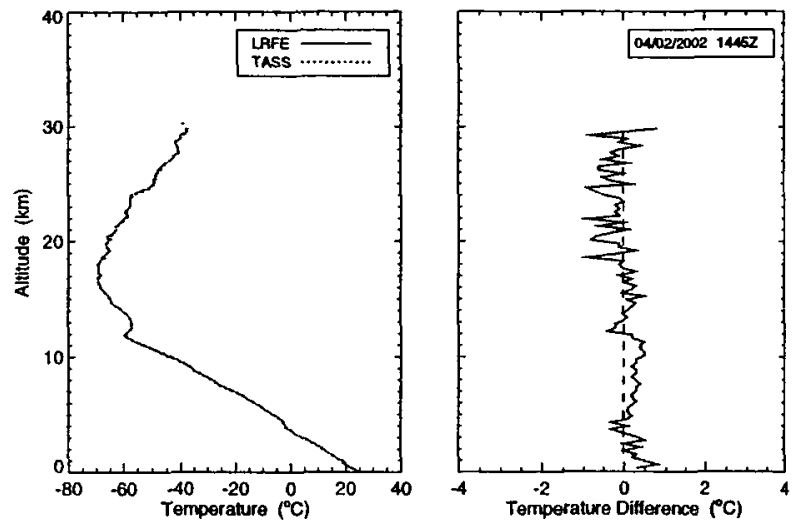

Figure 2. AMPS LRFE and TASS temperature profiles (left) and temperature difference (right) for test flight 7 (04/02/02 1445Z).

Table 3. Temperature difference statistics for nine of the ten AMPS LRFE/TASS comparison flights and total for all nine flights.

\begin{tabular}{c|ccc}
\multirow{2}{*}{$\begin{array}{c}\text { Flight } \\
\#\end{array}$} & \multicolumn{3}{|c}{ Temperature Difference $\left({ }^{\circ} \mathbf{C}\right)$} \\
\cline { 2 - 4 } & Mean & Std Dev & RMS \\
\hline 1 & 0.05 & 0.33 & 0.33 \\
2 & -0.08 & 0.40 & 0.40 \\
3 & 0.33 & 0.28 & 0.43 \\
4 & 0.35 & 0.63 & 0.72 \\
5 & N/A & N/A & N/A \\
6 & 0.09 & 0.44 & 0.45 \\
7 & 0.02 & 0.37 & 0.36 \\
8 & 0.32 & 0.39 & 0.50 \\
9 & 0.59 & 0.35 & 0.68 \\
10 & 0.12 & 0.41 & 0.42 \\
\hline Total & 0.19 & 0.46 & 0.49
\end{tabular}

Relative Humidity

TASS relative humidity $(\mathrm{RH})$ data was evaluated by determining the difference (AMPS LRFE - TASS) in RH at corresponding $305 \mathrm{~m}$ levels. Figure 3 shows the AMPS LRFE and TASS RH profiles and the RH difference for test flight 6 on 04/01/02 at 1615Z. Table 4 lists the RH difference statistics for the ten test flights and the total for all flights. The overall RMS RH difference was $6.31 \%$ RH. A previous study has shown that the AMPS LRFE system variability in RH was about $4.4 \% \mathrm{RH}^{\prime}$. It was possible that bad TASS RH data was present in flight 4 . Removal of this flight results in a RMS RH difference of $5.5 \% \mathrm{RH}$.
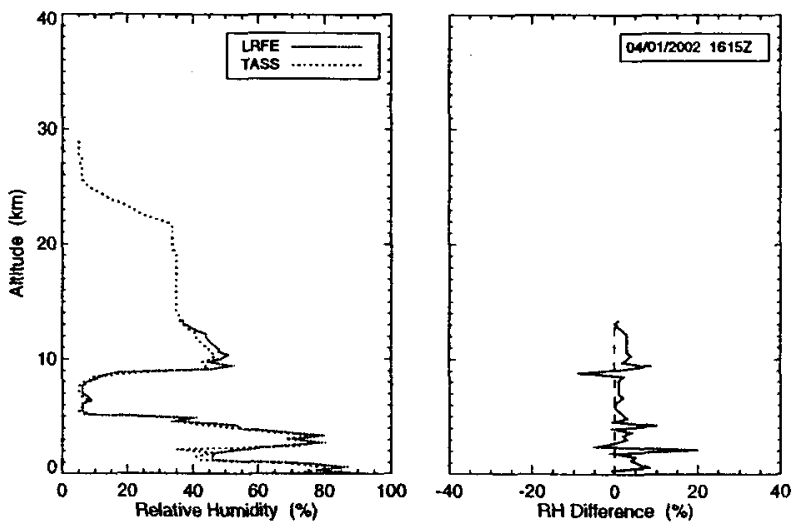

Figure 3. AMPS LRFE and TASS RH profiles (left) and RH difference (right) for test flight $6(04 / 01 / 02$ 1615Z).

Table 4. Relative humidity difference statistics for the ten AMPS LRFE/TASS comparison flights and total for all flights.

\begin{tabular}{c|ccc}
\multirow{2}{*}{$\begin{array}{c}\text { Fight } \\
\#\end{array}$} & \multicolumn{3}{|c}{ RH Difference (\% RH) } \\
\cline { 2 - 4 } & Mean & Std Dev & RMS \\
\hline 1 & -1.40 & 3.71 & 3.92 \\
2 & 2.40 & 5.98 & 6.38 \\
3 & 2.43 & 2.33 & 3.34 \\
4 & 0.07 & 11.51 & 11.37 \\
5 & 1.97 & 7.31 & 7.47 \\
6 & 2.39 & 4.04 & 4.65 \\
7 & 0.60 & 4.51 & 4.50 \\
8 & -6.63 & 4.36 & 7.90 \\
9 & 2.59 & 5.33 & 5.87 \\
10 & -1.90 & 3.19 & 3.19 \\
\hline Total & 0.27 & 6.40 & 6.31
\end{tabular}


Pressure

TASS pressure data was evaluated by determining the difference (AMPS LRFE - TASS) in pressure at corresponding $305 \mathrm{~m}$ levels. The pressure data for flight 5 , which had erroneous TASS temperature data, was not used since pressure is derived from temperature. Figure 4 shows the AMPS LRFE and TASS pressure profiles and the pressure difference for test flight 7 on $04 / 02 / 02$ at $1445 Z$. Note that the difference in pressure near the surface is approximately $9 \mathrm{hPa}$. This was typical for the nine test flights. Table 5 lists the pressure difference statistics for the nine test flights and the total for all flights. The overall RMS pressure difference was $4.20 \mathrm{hPa}$. The system variability of the AMPS LRFE in pressure is about $0.2 \mathrm{hPa}$.
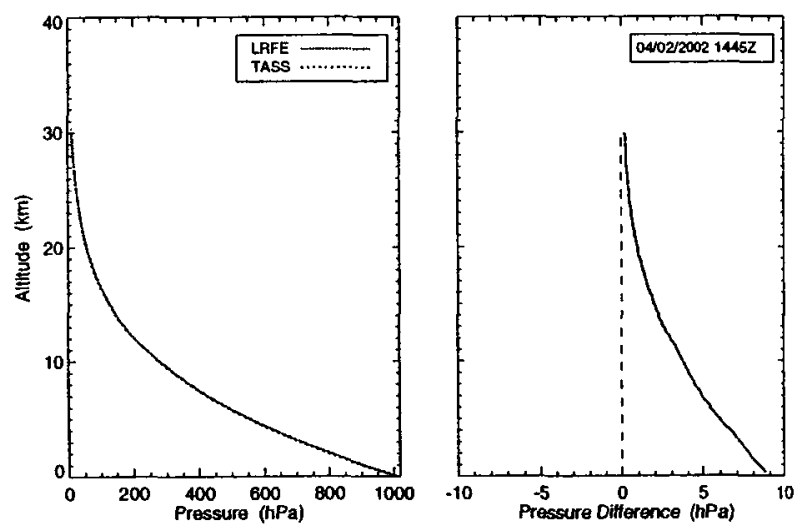

Figure 4. AMPS LRFE and TASS pressure profiles (left) and pressure difference (right) for test flight 7 (04/02/02 1445Z).

Table 5. Pressure difference statistics for the nine AMPS LRFE/TASS comparison flights and total for all flights.

\begin{tabular}{c|ccc}
\multirow{2}{*}{$\begin{array}{c}\text { Flight } \\
\#\end{array}$} & \multicolumn{3}{|c}{ Pressure Difference (hPa) } \\
\cline { 2 - 4 } & Mean & Std Dev & RMS \\
\hline 1 & -0.13 & 0.63 & 0.64 \\
2 & -0.18 & 0.76 & 0.78 \\
3 & 4.75 & 1.38 & 4.94 \\
4 & 6.51 & 4.54 & 7.92 \\
5 & N/A & N/A & N/A \\
6 & 2.91 & 2.41 & 3.77 \\
7 & 2.85 & 2.54 & 3.81 \\
8 & 2.98 & 2.51 & 3.89 \\
9 & 3.92 & 2.07 & 4.42 \\
10 & 2.67 & 2.30 & 3.52 \\
\hline Total & 2.88 & 3.07 & 4.20
\end{tabular}

Altitude

As stated earlier, pressure is not directly measured by the AMPS LRFE and TASS. It is derived from temperature, relative humidity, and altitude data. The current study showed that temperature and relative humidity compared well between the two systems. Therefore, an additional analysis was conducted to determine the quality of TASS altitude data. This was accomplished by comparing 1-second data from the five boom releases. Since the two sondes were at the same altitude during their ascent, altitude data could be compared as a function of time after balloon release. Figure 5 shows the altitude differences as a function of time for flight $6(04 / 01 / 021615 \mathrm{Z})$. There is a constant altitude difference of about 60 to $70 \mathrm{~m}$ for the entire profile. The other four boom release flights showed a similar systematic difference in altitude. The mean altitude difference for the five boom releases was $66 \mathrm{~m}$ $(217 \mathrm{ft})$. Figure 6 depicts a histogram of the altitude differences for the five flights.

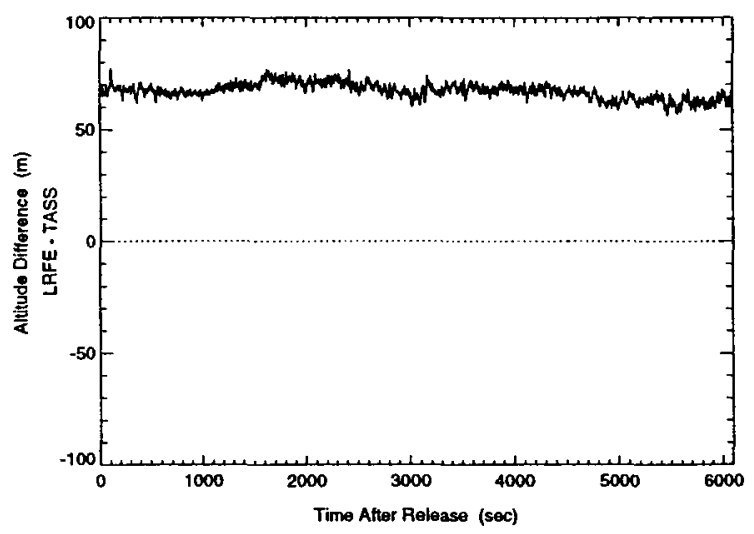

Figure 5. Altitude difference as a function of time for flight 6 (04/01/02 1615Z).

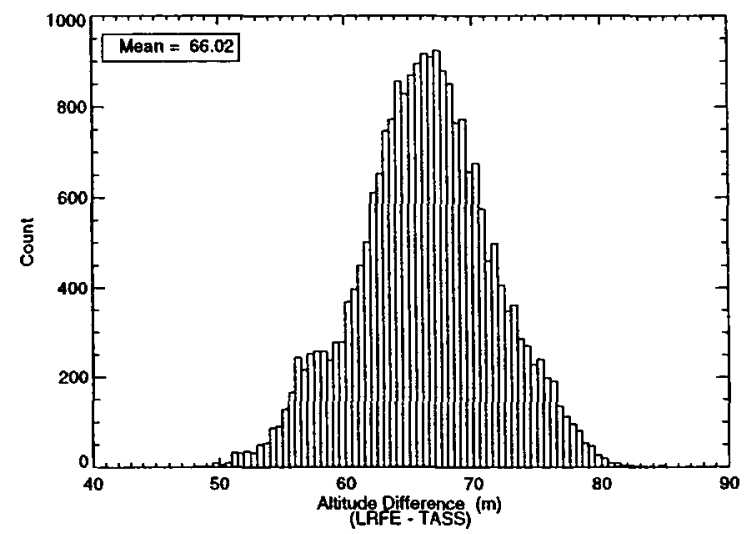

Figure 6. Histogram of altitude differences for the five boom releases.

4

American Institute of Aeronautics and Astronautics 
Using the 1-second data, pressure from both systems was also examined as a function of time after balloon release. Figure 7 shows that pressure differences are much smaller when plotted as a function of time instead of as a function of altitude. Pressure differences were generally less than $0.5 \mathrm{hPa}$, as opposed to differences as high as $9 \mathrm{hPa}$ (see Figure 4).

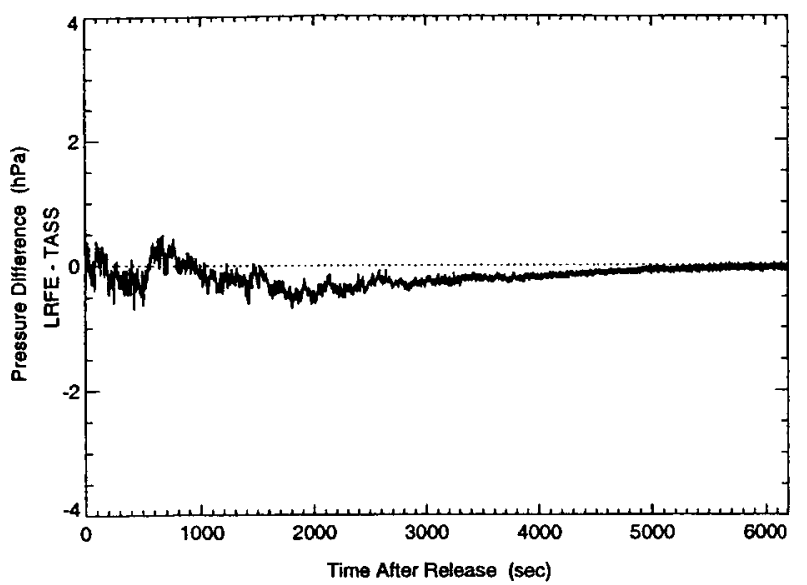

Figure 7. Pressure difference between the AMPS LRFE and TASS as a function of time for flight 7 (04/02/02 1445Z).

Since pressure compared very well when examined as a function of time, and that TASS altitudes were consistently 60 to $70 \mathrm{~m}$ lower than AMPS LRFE altitudes, it was concluded that there was a systematic error in altitude in one or both of the systems. Pressure is not influenced by a systematic error in altitude because it is derived using the depth of an altitude layer $\left(\Delta\right.$ alt $=$ alt $_{2}-$ alt $\left._{1}\right)$. However, if a systematic error in altitude is present, the pressure will be reported at the incorrect altitude level. For example, a $60 \mathrm{~m}$ error in altitude will mean that the pressure at the $200 \mathrm{~m}$ level will be reported at the $140 \mathrm{~m}$ level in the data files.

Analysis of these findings by the TASS vendor resulted in the discovery of an incorrect GPS setting in the TASS software. Points determined from GPS are in relation to a reference frame. For TASS, this reference frame is the World Geodetic System 1984 (WGS84) model ${ }^{2}$. The TASS GPS sonde measures points above or below the WGS84 ellipsoid (geodetic height). To determine the orthometric height (height above mean sea level) for a particular coordinate, the height between mean sea level (the geoid) and the ellipsoid is needed. The TASS software contained an incorrect setting for this value. However, it was easily fixed and subsequent test flights to verify software updates were conducted.
TASS Software Update Analysis

The geoid setting in the TASS software was fixed in September 2002 and a software update was installed in early 2003 that included a new method to calculate geopotential altitude for improved pressure derivation. Five test flights were conducted in May and June of 2003 to verify the software updates. Three of these flights were a simultaneous release of an AMPS LRFE and TASS balloon. The other two flights consisted of an AMPS LRFE sonde and TASS sonde attached to the same balloon, with the AMPS LRFE sonde suspended about $15 \mathrm{~m}(50 \mathrm{ft})$ below the TASS sonde. Table 6 lists the five test flights. Once again, data was compared at corresponding $305 \mathrm{~m}$ levels.

Table 6. Listing of TASS/AMPS LRFE comparison flights to verify TASS software updates.

\begin{tabular}{ccc}
\hline Flight \# & Date (Time) & Configuration \\
\hline 1 & $\begin{array}{c}05 / 27 / 03 \\
(1545 \mathrm{Z})\end{array}$ & Simultaneous Release \\
\hline 2 & $\begin{array}{r}05 / 28 / 03 \\
(1500 \mathrm{Z})\end{array}$ & Simultaneous Release \\
\hline 3 & $\begin{array}{c}05 / 30 / 03 \\
(1500 \mathrm{Z})\end{array}$ & Simultaneous Release \\
\hline 4 & $\begin{array}{c}06 / 18 / 03 \\
(1500 \mathrm{Z})\end{array}$ & Tie-on \\
\hline 5 & $\begin{array}{c}06 / 23 / 03 \\
(1500 \mathrm{Z})\end{array}$ & Tie-on \\
\hline
\end{tabular}

Analysis of data from these five test flights indicated that temperature, relative humidity, and wind data were comparable or slightly better than the pre-software update analysis results. Pressure differences had greatly improved from RMS differences of $4.20 \mathrm{hPa}$ to 0.66 $\mathrm{hPa}$. However, it was expected that RMS differences would be comparable to the AMPS LRFE system variability of $0.2 \mathrm{hPa}$. Figure 8 shows the AMPS LRFE and TASS pressure profiles and the pressure difference for post-software update test flight 5 on $06 / 23 / 03$ at 1500Z. Differences near the surface are slightly less than $2 \mathrm{hPa}$ and fall off towards zero with altitude. Future studies will be conducted to determine possible reasons for the pressure differences seen in this analysis. 

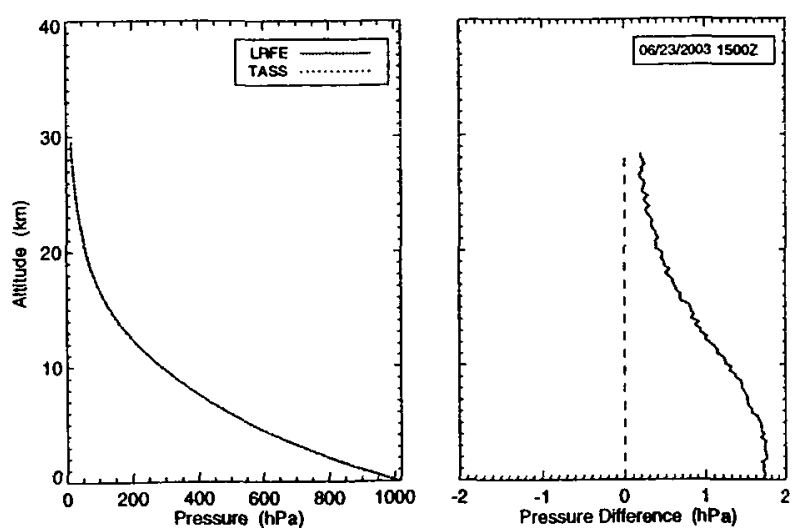

Figure 8. AMPS LRFE and TASS pressure profiles (left) and pressure difference (right) for post-software update test flight $5(06 / 23 / 03$ 1500Z).

The two tie-on flights (post-software update flights 4 and 5) presented the opportunity to examine altitude differences as a function of time, much like in the presoftware update boom releases. Altitude differences as a function of time are shown in Figure 9 for tie-on flight 4 on $06 / 18 / 03$ at $1500 \mathrm{Z}$. The approximately $17 \mathrm{~m}$ difference in altitude corresponds to the separation distance of the two sondes $(\sim 15 \mathrm{~m})$, indicating that the GPS settings in the TASS software have been corrected.

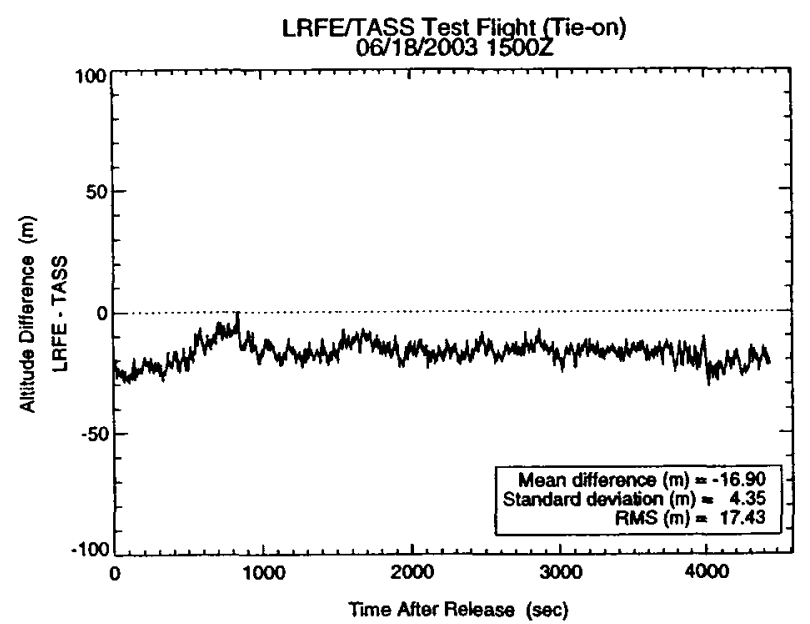

Figure 9. AMPS LRFE and TASS altitude difference as a function of time for post-software update tie-on flight $4(06 / 18 / 03$ 1500Z).

\section{SUMMARY}

A study was performed to determine the quality of thermodynamic and wind data reported by TASS. Ten comparison flights between the AMPS LRFE and TASS were conducted at the ETR in early 2002. Analysis of data from these test flights indicated that temperature, relative humidity, and wind compared favorably. However, pressure differences were much more than expected, with RMS differences of $4.2 \mathrm{hPa}$. Examination of altitude data as a function of time showed that TASS altitudes were generally 60 to $70 \mathrm{~m}$ less than AMPS LRFE altitudes. This was causing TASS data to be reported at levels 60 to $70 \mathrm{~m}$ lower than the AMPS LRFE data. Inspection of TASS software showed that GPS settings were incorrectly entered and software updates to fix the problem were installed in early 2003 . Subsequent testing to verify software updates showed that TASS altitudes were comparable to AMPS LRFE altitudes and that pressure differences were reduced from RMS values of $4.2 \mathrm{hPa}$ to $0.66 \mathrm{hPa}$. However, it was expected that RMS differences would be comparable to the AMPS LRFE system variability of $0.2 \mathrm{hPa}$. Future studies are planned that will address this issue.

\section{REFERENCES}

1. Leahy, F., and Overbey, G., "An Analysis of the Automated Meteorological Profiling System Low Resolution Flight Element," $42^{\text {nd }}$ Aerospace Sciences Meeting and Exhibit, 5-8 January 2004, Reno, Nevada.

2. Military Standard, Department of Defense World Geodetic System (WGS), MIL-STD2401, 11 January 1994.

\section{ACKNOWLEDGEMENT}

The author wishes to thank members of Computer Science Raytheon's weather support team at the ETR for their cooperation and hard work in conducting testing and processing data for this analysis. 